\title{
An improved glycerol biosensor with an Au-FeS-NAD-glycerol-dehydrogenase anode
}

\author{
Aishwarya Mahadevan ${ }^{a}$ and Sandun Fernando ${ }^{a^{*}}$ \\ ${ }^{a}$ Department of Biological and Agricultural Engineering, 303C Scoates Hall, Texas A\&M University, \\ College Station, TX 77843, USA \\ ${ }^{*}$ Corresponding Author's Email address: sfernando@tamu.edu (S. Fernando) \\ †Phone: (979) 845 9793, Fax: (979) 8623442
}

\begin{abstract}
An improved glycerol biosensor was developed via direct attachment of $\mathrm{NAD}^{+}$-glycerol dehydrogenase coenzyme-apoenzyme complex onto supporting gold electrodes, using novel inorganic iron (II) sulfide (FeS)-based single molecular wires. Sensing performance factors, i.e., sensitivity, a detection limit and response time of the FeS and conventional pyrroloquinoline quinone (PQQ)-based biosensor were evaluated by dynamic constant potential amperometry at $1.3 \mathrm{~V}$ under non-buffered conditions. For glycerol concentrations ranging from 1 to $25 \mathrm{mM}$, a $77 \%$ increase in sensitivity and a $53 \%$ decrease in detection limit were observed for the FeS-based biosensor when compared to the conventional PQQbased counterpart. The electrochemical behavior of the FeS-based glycerol biosensor was analyzed at different concentrations of glycerol, accompanied by an investigation into the effects of applied potential and scan rate on the current response. Effects of enzyme stimulants $\left(\left(\mathrm{NH}_{4}\right)_{2} \mathrm{SO}_{4}\right.$ and $\left.\mathrm{MnCl}_{2} .4 \mathrm{H}_{2} \mathrm{O}\right)$ concentrations and buffers/pH (potassium phosphate buffer $\mathrm{pH} 6-8$, Tris buffer $\mathrm{pH} 8-10$ ) on the current responses generated by the $\mathrm{FeS}$-based glycerol biosensor were also studied. The optimal detection conditions were $0.03 \mathrm{M}\left(\mathrm{NH}_{4}\right)_{2} \mathrm{SO}_{4}$ and $0.3 \mu \mathrm{M} \mathrm{MnCl}_{2} .4 \mathrm{H}_{2} \mathrm{O}$ in non-buffered aqueous electrolyte under stirring whereas under non-stirring, Tris buffer at $\mathrm{pH} 10$ with $0.03 \mathrm{M}\left(\mathrm{NH}_{4}\right)_{2} \mathrm{SO}_{4}$ and $30 \mu \mathrm{M} \mathrm{MnCl}_{2} .4 \mathrm{H}_{2} \mathrm{O}$ were found to be optimal detection conditions. Interference by glucose, fructose, ethanol, and acetic acid in glycerol detection was studied. The observations indicated a promising enhancement in glycerol detection using the novel FeS-based glycerol sensing electrode compared to the conventional PQQbased one. These findings support the premise that FeS-based bioanodes are capable of biosensing glycerol successfully and may be applicable for other enzymatic biosensors.
\end{abstract}

Keywords - Glycerol biosensor, Glycerol dehydrogenase, Enzyme immobilization, FeS Molecular wire, Self-assembly, Cyclic voltammetry

\subsection{Introduction}

An intensive interest in glycerol determination exists due to its extensive utility in the medical, food and biofuels industries. The conventional methods used for glycerol detection are expensive, complex, and often lack enough specificity. This issue has led to a quest for an accurate, rapid, and inexpensive method for glycerol quantification. One of the sought-after methods for analyte detection is biosensing. Enzymatic electrochemical biosensors especially have gathered considerable attention due to their simplicity, accuracy, high selectivity, and speediness in rendering results.

Enzymatic electrochemical biosensors are analytical devices that integrate an enzyme as the active sensing element within an electrochemical transducing system (Ronkainen et al. 2010). In enzymatic electrochemical biosensors, the electrical signal generated as a result of an electrochemical redox reaction that occurs at the active site is harnessed to produce inferences for the analyte concentrations. The dependency of the sensing system on the resultant electrical signals make electron-transfer between an active site of the immobilized enzyme and the electrode surface a key factor that decides the efficiency of the biosensor (Marcus and Sutin 1985).

Enzymes that allow the electrochemical cell, i.e., the core of the sensing system, to operate must be "immobilized" near the anode and cathode in order to work properly. If not immobilized, these enzymes will diffuse into the cell's electrolyte, and most of the liberated electrons will not reach the electrodes, thus 
compromising its effectiveness. The overall effectiveness of all enzyme-based electrochemical devices is dependent on the ability of the molecules that attach enzymes to the electrode to successfully harvest and transport the charges from the outer oxidizing point (enzyme active-site) to the inner electrode surface.

When these enzymes are wired to electrodes (outside a living cell or ex vivo), their ability to harness these electrons (or electricity) diminishes significantly due to the thermodynamic limitations that are associated with the coenzymes (essential for proper functioning of the enzyme). The common coenzymes, nicotinamide-adenine-dinucleotide (NAD) and Flavin-adenine-dinucleotide (FAD), are resistant to cyclic oxidation and reduction ex vivo, and they require special molecules known as electron mediators to help extract electrons from the cofactor to transfer to the final target. Since known electron mediators do not have the correct combination of prosthetic groups to anchor the coenzyme from/at one end and the base electrode from/at the other, molecules with appropriate functional groups need to be introduced to the wiring scheme to fulfill the anchoring function. Figure $1 \mathrm{~A}(\mathrm{a})$ depicts a commonly used conventional wiring scheme that comprises cystamine, pyrroloquinoline quinone (PQQ), and boronic acid, to attach the NAD coenzyme-based apoenzyme onto a metal electrode for sensing and biofuel cell applications.

The outcome of such a long wiring scheme is high ohmic resistance, which leads to constrained electron transport (Johnston et al. 2007; Park et al. 1999; Reed et al. 1997), resulting in sensors with low sensitivity (Minteer et al. 2007; Reed et al. 1997; Riklin et al. 1995).

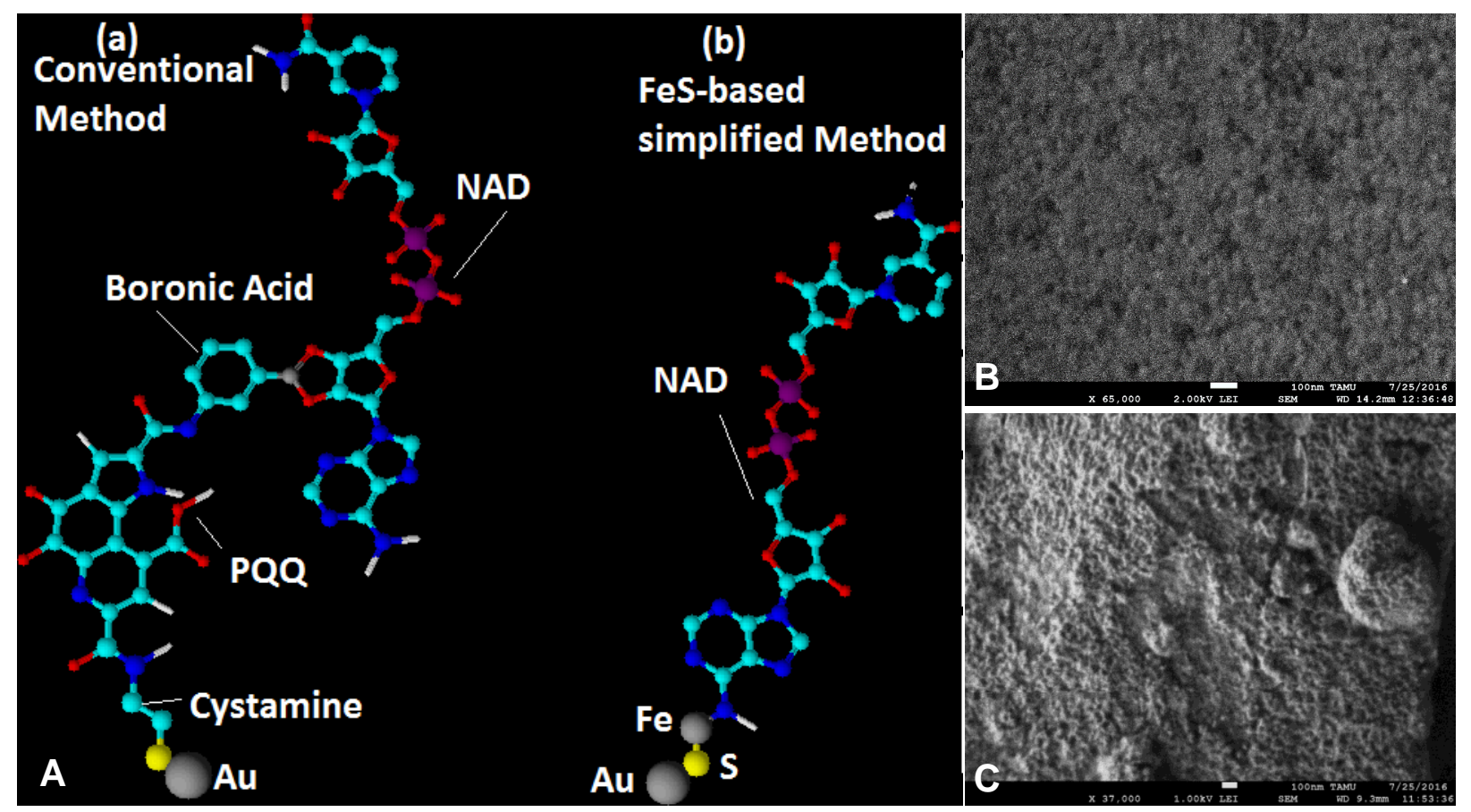

Fig. 1: (A) A schematic of wiring systems. (a) Complex conventional wiring of the coenzyme NAD ${ }^{+}$to a gold electrode using a series of molecules, including a cystamine linker, a PQQ mediator, and a phenyl boronic acid linker; (b) Simplified wiring of a NAD ${ }^{+}$coenzyme directly onto the gold electrode by a multi-functional mediator, FeS. Reprinted with permission from ref (Mahadevan et al. 2016). Copyright 2015 Elsevier B.V; Surface morphology of (B) bare Au surface and (C) an enzyme immobilized Au surface examined via FE-SEM.

Interestingly, nature has found a way to circumvent overpotential (activation, transfer, and resistance overpotentials) and anchoring issues by using unique [Fe-S] clusters that have electron mediation properties (so as to cyclically reduce and oxidize between $\mathrm{Fe}^{2+} / \mathrm{Fe}^{3+}$ while extracting electrons from the coenzyme molecule as soon as the coenzyme is reduced and disposing of the electrons to the adjacent electron acceptor); a very short length to reduce the electron travel distance (thereby reducing the internal 
resistance of the conductor); and the correct prosthetic groups to anchor onto adjoining chemical moieties (sulfur that coordinates with metal centers (Graham and Dingman 2006; Love et al. 2005; Mrksich et al. 1996; Tour et al. 1995; Zhong and Porter 1994) and onto proteins with cysteinyl residues (Meyer 2008) or iron that coordinates with the heterocyclic nitrogen atoms (Cline et al. 1985; Lavrenova et al. 1986; Marlin et al. 1999) such as those present in coenzymes and mitochondrial peptides).

Our approach to improving electron transport in enzymatic electrodes ex vivo is to use iron-sulfur moieties (iron sulfides or [Fe-S] complexes) and directly attach the coenzyme-dependent redox enzyme systems onto the electrode, so that activation, transfer and resistance overpotentials are significantly reduced. The obstacle that prevents a replication of the core of the natural electron transport chain has been an inability to duplicate the functionality of iron-sulfur linker molecules ex vivo. Iron sulfides (and [Fe-s] complexes) are quite unstable in an aqueous environment, and all attempts to attach [Fe-S] complexes onto metal surfaces in an aqueous environment have thus far failed. However, we were able to address this key knowledge gap. Our breakthrough came as a result of performing an iron (II) sulfide (FeS) dissolution and attachment onto a gold electrode in a 100\% ethanol environment (Fig. 1A(b)) (Mahadevan et al. 2016).

The key objective of the current study was to develop a working glycerol biosensor fabricated via the novel iron-sulfur mediated molecular wiring scheme, then optimize it and compare its sensing performance to those of a conventionally wired PQQ-based glycerol biosensor.

\subsection{Materials and Methods}

\subsection{Reagents and apparatus}

$\mathrm{NAD}^{+}$-dependent glycerol dehydrogenase from Cellulomonas sp. (EC.1.1.1.6), B-nicotinamide adenine dinucleotide $\left(\mathrm{NAD}^{+}\right)$, glutaraldehyde, iron (II) sulfide (FeS), pyrroloquinoline quinone, cystamine dihydro chloride, 3-aminophenylboronic acid monohydrate, HEPES buffer, glycerol $\geq 99 \%$, glucose and fructose were purchased from Sigma-Aldrich in the U.S.. 1-Ethyl-3-(3-dimethylaminopropyl) carbodiimide (EDC) and $\mathrm{N}$-Hydroxysuccinimide (NHS) were purchased form Thermo Fisher Scientific. A gold electrode polishing kit was purchased from $\mathrm{CH}$ Instruments, Inc. A $50 \mathrm{mM} \mathrm{KOH}$ solution made in 30 wt $\% \mathrm{H}_{2} \mathrm{O}_{2}$ and $50 \mathrm{mM} \mathrm{KOH}$ solution made in pure water were used in the gold cleaning procedure. FeS was suspended in $\geq 99.5 \%$ ethanol, and cystamine dihydro chloride was dissolved in pure water. B-NAD ${ }^{+}, \mathrm{GIDH}$, and glutaraldehyde solutions were prepared in a $0.1 \mathrm{M}$ phosphate buffer $(\mathrm{pH}=7)$; $\mathrm{PQQ}$ and 3aminophenylboronic acid solutions were prepared using $0.1 \mathrm{M} \mathrm{HEPES}$ buffer $(\mathrm{pH} 7.2)$ in the presence of $5 \mathrm{mM}$ EDC and $2.5 \mathrm{mM}$ NHS. Water containing the enzyme stimulants viz. $\left(\mathrm{NH}_{4}\right)_{2} \mathrm{SO}_{4}$ and $\mathrm{MnCl}_{2} \cdot 4 \mathrm{H}_{2} \mathrm{O}$ was used as the point of reference carrier electrolyte as described previously(Mahadevan et al. 2015). Molecular-biology-grade water (termed "pure water" in this paper) obtained from Sigma-Aldrich was used to prepare all the aqueous-based solutions and for rinsing and cleaning throughout this study.

Two-millimeter size gold-disk working electrodes, $\mathrm{Ag} / \mathrm{AgCl}$ reference electrodes, and Pt auxiliary electrodes were purchased from $\mathrm{CH}$ Instruments, Inc. All experiments were carried out in an electrochemical cell that was set up using a C3 cell stand from BASi. CHI8003D Potentiostat from $\mathrm{CH}$ Instruments, Inc. was used for electrochemical electrode cleaning and electrode testing methods.

\subsection{Glycerol Dehydrogenase electrode(s) fabrication}

Two different glycerol oxidizing electrodes were fabricated, based on a FeS-based wiring system and a PQQ-based wiring system to tether the GIDH enzyme onto the gold electrode. A dip-coating method was used to fabricate the FeS-based and PQQ-based enzymatic biosensors applying the principle of layer-bylayer self-assembly. A gold (Álvarez-González et al.) working electrode cleaning procedure included polishing Au electrodes using 1200 grit Carbimet disk (used occasionally to remove scratches); 1, 0.3, and 0.05 micron alumina in a sequence followed by sonication to remove alumina particles; dipping the Au electrodes in a $50 \mathrm{mM} \mathrm{KOH}$ solution made in $30 \mathrm{wt} \% \mathrm{H}_{2} \mathrm{O}_{2}$ for 30 minutes, followed by rinsing with pure water; and finally, 5 cyclic voltammetry sweeps in the $50 \mathrm{mM} \mathrm{KOH}$ solution made of pure water followed by thorough rinsing with pure water. For fabrication of FeS-based bioanode, the clean $\mathrm{Au}$ 
electrodes were first dipped into a $0.3 \mathrm{M} \mathrm{FeS}$-in-ethanol solution for $2 \mathrm{Hrs}$. The FeS-tethered $\mathrm{Au}$ electrodes were immersed in $1 \mathrm{mM}$ of $B-N_{A} D^{+}$for $2 \mathrm{Hrs}$ after which, the FeS-NAD-tethered Au electrodes were dipped in $1 \mathrm{mg} \mathrm{mL}^{-1}$ of GIDH for $2 \mathrm{Hrs}$. The resulting FeS-NAD-GIDH functionalized electrodes were finally treated with $10 \%(\mathrm{v} / \mathrm{v})$ glutaraldehyde for $20 \mathrm{~min}$ to crosslink and secure the protein (enzyme) layer. The PQQ-based bioanode was similarly fabricated by sequential dipping of the Au electrode in $0.1 \mathrm{M}$ cystamine dihydrochloride solution for $1 \mathrm{Hr}, 3 \mathrm{mM}$ solution of $\mathrm{PQQ}$ for $2 \mathrm{Hrs}, 1 \mathrm{mM}$ 3-aminophenylboronic acid solution for $2 \mathrm{Hrs}, 1 \mathrm{mM}$ of B-NAD solution for $2 \mathrm{Hrs}, 1 \mathrm{mg} \cdot \mathrm{mL}^{-1} \mathrm{GIDH}$ for $2 \mathrm{Hrs}$ and a final $20 \mathrm{Min}$ treatment with $10 \%(\mathrm{v} / \mathrm{v})$ glutaraldehyde. Note that, each sequential step was followed by a rinsing of the monolayer-tethered Au electrode with pure water. The surface morphology of the bare Au surface and the enzyme immobilized Au surface was examined using FE-SEM analysis (Fig. 1 B \& C).

\subsection{Electrochemical measurements}

Biosensor performance factors viz. sensitivity, detection limit, and response time were determined using dynamic constant potential amperometry (CPA). CPA for FeS, and PQQ- based electrodes was performed for glycerol detection under stirred conditions at $1.3 \mathrm{~V}$ vs. $\mathrm{Ag} / \mathrm{AgCl}$. After stabilization of the baseline current, $2 \mu \mathrm{L}$ of $10 \mathrm{M}$ glycerol was injected into the aqueous reaction solution containing enzyme stimulants $-0.03 \mathrm{M}$ and $0.3 \mu \mathrm{M}$ (hereinafter referred to as benchmark concentrations) of $\left(\mathrm{NH}_{4}\right)_{2} \mathrm{SO}_{4}$ and $\mathrm{MnCl}_{2} \cdot 4 \mathrm{H}_{2} \mathrm{O}$, respectively. Sensitivity was calculated from the slope of the linear portion in the calibration curves, using simple linear regression. The lower limit of detection (LOD) was calculated using the 3 sigma method (Vanegas et al. 2014). Response time was obtained by taking the mean of the $95 \%$ steady state response time of 3 successive step changes over the linear range being tested.

Determination of optimal conditions under which the FeS-based biosensor generates maximum current response was electrochemically studied using cyclic voltammetry and constant potential amperometry. The effects of applied potential, scan rate, enzyme stimulants concentrations, buffer and $\mathrm{pH}$ on the FeSbased electrode were investigated. For all the studies, except for the study on enzyme stimulants, benchmark concentrations of enzyme stimulants were used. Further, recognizing that the potential application of this biosensor is in the beverage industry, the possible interference of glucose, fructose, ethanol, and acetic acid during glycerol detection was studied, using cyclic voltammetry at $0-1.5 \mathrm{~V}$ under non-buffered conditions with benchmark concentrations of enzyme stimulant concentrations as well as in Tris buffer $/ \mathrm{pH}$ and optimized enzyme stimulant concentrations. All of the electrochemical measurements were conducted in three replications.

\subsection{Results and Discussion}

\subsection{Glycerol biosensor performance}

Glycerol biosensors that involve several glycerol-selective enzymes, glycerol oxidase, glycerol kinase, glycerol-3-phosphate dehydrogenase and glycerol dehydrogenase associated with different types of base electrodes and immobilization techniques have been reported on previously (Álvarez-González et al. 2000; Eftekhari 2001; Katrlík et al. 2006; Niculescu et al. 2003). However, these biosensors were fabricated via traditional enzyme tethering methods (the majority of them utilize polymer -mediated enzyme immobilization). Glycerol biosensors based on immobilization of NAD+-dependent glycerol dehydrogenase have previously been reported with very low detection limits (LOD): $0.005 \mathrm{mM}$ in the presence of $\mathrm{K}^{+}$(Prodromidis et al. 1996), $4.3 \times 10^{-4} \mathrm{mM}$ (Álvarez-González et al. 2000), $1 \times 10^{-3} \mathrm{mM}$ (Eftekhari 2001), $9 \times 10^{-4} \mathrm{mM}$ and $1 \times 10^{-4} \mathrm{mM}$ (Niculescu et al. 2003), and $2.2 \times 10^{-3} \mathrm{mM}$ (Radoi et al. 2007).

In this study, dynamic constant potential amperometry (CPA) was performed for the FeS-based and $P Q Q$-based biosensors to show their respective responses to the successive increments of $1 \mathrm{mM}$ glycerol from 1 to $25 \mathrm{mM}$ at an applied potential of $1.3 \mathrm{~V}$ (Fig. 2A). 

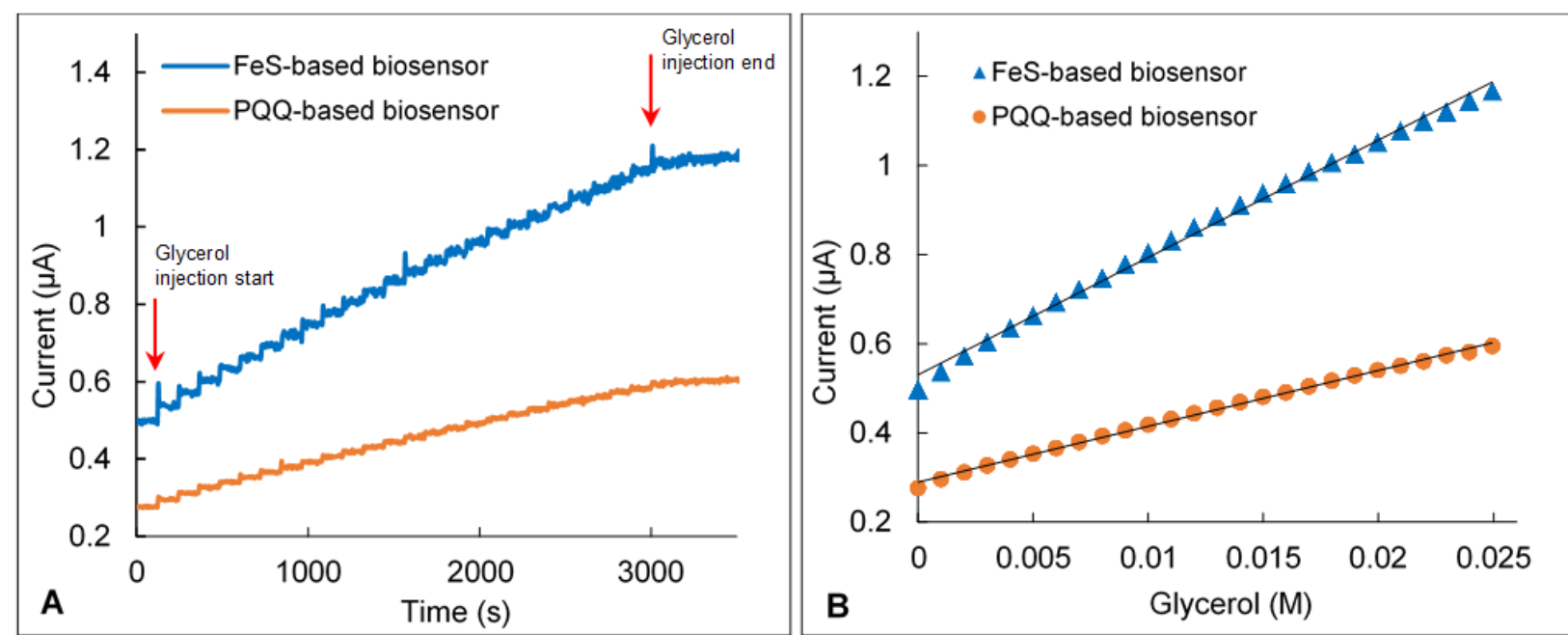

\begin{tabular}{|c|c|c|c|c|c|c|}
\hline \multirow[t]{2}{*}{ Wiring Type } & \multicolumn{2}{|c|}{ Sensitivity $(\mu A / M)$} & \multicolumn{2}{|c|}{ LOD (M) } & \multicolumn{2}{|c|}{ Response Time (s) } \\
\hline & Mean & Std.Dv & $10^{-4}$ Mean & 10-4 Std.Dv & Mean & Std.Dv \\
\hline FeS-based & 24.9 & 1.66 & 1.58 & 0.31 & 1.52 & 0.22 \\
\hline PQQ-based & 14.1 & 1.73 & 3.36 & 0.4 & 0.57 & 0.07 \\
\hline $\begin{array}{l}\% \text { Change } \\
\text { c }\end{array}$ & & & & & & \\
\hline
\end{tabular}

Fig. 2: (A) Amperometric responses to increments of $0.001 \mathrm{M}$ glycerol at $E=1.3 \mathrm{~V}$; (B) Calibration plots for current responses generated by the FeS-based biosensor and PQQ-based biosensor as a function of glycerol concentration; (C) Summary of the biosensor performance obtained from a dynamic CPA test.

Fig. 2B shows the calibration plot of current response to glycerol concentration derived from this study. The slope of the calibration plot represents the sensitivity of the biosensor (Bardeletti et al. 1991). The greater the slope, the higher is the sensitivity of biosensor. Both FeS-based and PQQ-based biosensors were found to respond linearly to glycerol concentrations with sensitivities $14 \mu \mathrm{A} \cdot \mathrm{M}^{-1}$ for $\mathrm{PQQ}$-based biosensor and $25 \mu \mathrm{A} . \mathrm{M}^{-1}$ for FeS-based biosensor obtained from the slopes of the calibration plots. LOD was calculated using 3 sigma method were found to be $0.34 \mathrm{mM}$ for PQQ-based biosensor and $0.16 \mathrm{mM}$ for FeS-based biosensor. These findings confirm that the PQQ-based and FeS-based bioanodes can be reliably used to measure glycerol concentrations as low as $0.34 \mathrm{mM}$ and $0.16 \mathrm{mM}$, respectively. Response times were calculated as $0.6 \mathrm{~s}$ for the PQQ-based biosensor and $1.5 \mathrm{~s}$ for the FeS-based biosensor. The performance factors for both types of biosensors obtained from the CPA test are summarized here in Fig. 2C.

These results indicate a 77\% increase in sensitivity, a 53\% decrease in LOD, and a 167\% increase in response time for a FeS-based biosensor when compared to a PQQ-based biosensor for glycerol analysis. While the sensitivity and LOD of the FeS-based biosensor showed significant improvement, the increase in response time for the FeS-based biosensor was unanticipated, and is yet to be fully elucidated. The overall improvements are promising and support the premise of this study, namely, that the electron transfer characteristics of FeS-based bioanodes are favorable when compared to the PQQbased conventional bioanodes. As reported in our previous communication (Mahadevan et al. 2016), the improved electron transfer characteristics of FeS-based bioanodes are due to an reduced internal resistance of the enzymatic electrode resulting from the shorter FeS single-molecular-wire, opposed to the conventional PQQ-based composite wiring system that requires a series of biomolecules to foster enzyme attachment and the ability of $\mathrm{FeS}$ to be a single-molecular anchoring agent to mediate electron shuttling between $\mathrm{NAD}^{+}$and the supporting electrode. 


\subsection{Electrochemical behavior of a FeS-based biosensor}

The electrochemical behavior of the FeS-based glycerol biosensor was characterized by cyclic voltammetry. Fig. 3A shows a typical cyclic voltammogram (CV) obtained with the FeS-based biosensor in pure water containing enzyme stimulants with concentrations of glycerol ranging from 0.001 to $1 \mathrm{M}$. The CV labelled "a" shows the electrochemical behavior of the $\left(\mathrm{NH}_{4}\right)_{2} \mathrm{SO}_{4}$ enzyme stimulant, whereas b-e shows the current response under increasing glycerol concentrations. It should be noted that with increasing glycerol concentrations, an increase in the oxidation peak current at $1.3 \mathrm{~V} \mathrm{vs}$. $\mathrm{Ag} / \mathrm{AgCl}$ was observed. This result indicates that glycerol oxidation takes place via the redox reaction of $\left(\mathrm{NH}_{4}\right)_{2} \mathrm{SO}_{4}$. The effect of applied potential that ranges from 0 to $1.5 \mathrm{~V} \mathrm{vs}$. $\mathrm{Ag} / \mathrm{AgCl}$ on the current response of the FeS-based biosensor in the presence of $1 \mathrm{M}$ glycerol is shown in Fig. 3B. Current remains nearly constant from 0 to $0.8 \mathrm{~V}$, and from $1 \mathrm{~V}$ onwards current linearly increases with an increasingly applied potential and the highest current obtained at $1.5 \mathrm{~V}$.
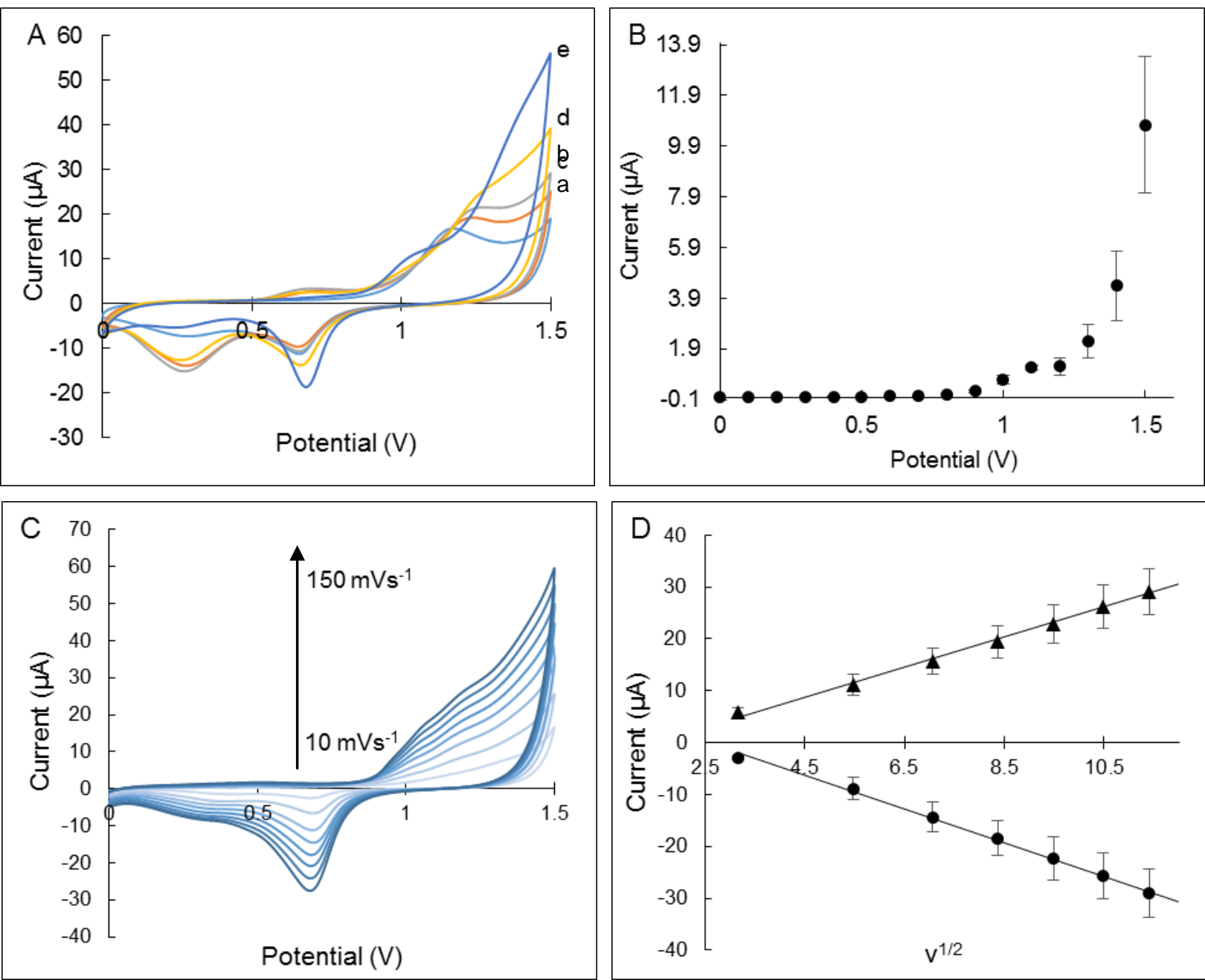

Fig. 3. (A) Cyclic voltammograms for FeS-based biosensor in increasing concentrations of glycerol $(\mathrm{a}-0 \mathrm{M}, \mathrm{b}-$ $0.001 \mathrm{M}, \mathrm{c}-0.01 \mathrm{M}, \mathrm{d}-0.1 \mathrm{M}$ and $\mathrm{e}-1 \mathrm{M}$ ) diluted with water containing enzyme stimulants at benchmark concentrations. Scan rate is $50 \mathrm{mV} / \mathrm{s}$; (B) Effect of applied potential, ranging from 0 to $1.5 \mathrm{~V}$ on the current response of the FeS-based biosensor in the presence of $1 \mathrm{M}$ glycerol; (C) Effect of scan rates (10, 30, 50, 70, 90, 110, 130, and 150) $\mathrm{mVs}^{-1}$ on the current response of the FeS-based biosensor in the presence of $1 \mathrm{M}$ glycerol where the color intensity of the CV scan increases with an increasing scan rate in the figure; (D) Anodic and cathodic peak currents plotted with respect to the square root of the scan rate $\left(v^{1 / 2}\right)$. 
The type of controlled processes that occur during glycerol oxidation at the Au-FeS-NAD-GIDH electrode was elucidated by studying the effects of the scan rate $\left(10 \mathrm{mVs}^{-1}\right.$ to $\left.150 \mathrm{mVs}^{-1}\right)$ on the peak current, as shown in Fig. 3C. Fig. 3D shows the changes of the anodic and cathodic peak currents under $1 \mathrm{M}$ glycerol with the square root of the scan rate $\left(\mathrm{v}^{1 / 2}\right)$. The anodic and cathodic peak currents for glycerol increased linearly with the square root of the scan rate with a high correlation of $\sim 0.996$, indicating that the electrode reaction of glycerol was diffusion-controlled. Reactions under diffusion-controlled (or diffusion-limited) conditions occur so quickly that the reaction rate is determined by the rate of transport of the reactants through the reaction solution (Atkins 1998). This study thus further proves the redox mediation ability of the FeS to efficiently shuttle electrons between the enzyme active site and the gold electrode; and it proves that the layer of enzyme- immobilized molecular wires is permeable to glycerol for a redox reaction. Furthermore, with an increasing scan rate, the anodic and cathodic peak potentials shifted toward the positive and negative quadrants, respectively, indicating charge transfer kinetics limitations.

\subsection{Effect of enzyme stimulants}

Glycerol dehydrogenase catalyzes the oxidation of glycerol to form glycerone by using $\mathrm{NAD}^{+}$as the cofactor/coenzyme. The catalytic efficiency of the reaction is improved in the presence of $\left(\mathrm{NH}_{4}\right)_{2} \mathrm{SO}_{4}$ and $\mathrm{MnCl}_{2} \cdot 4 \mathrm{H}_{2} \mathrm{O}$ due to their stimulatory effects on the enzyme. Previously, we found that the enzyme stimulants are indispensable for glycerol detection using the wired bioanodes under study. Substantial

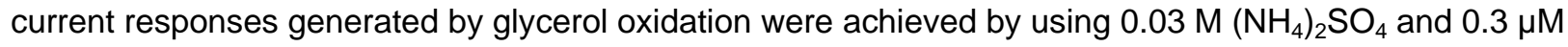
$\mathrm{MnCl}_{2} \cdot 4 \mathrm{H}_{2} \mathrm{O}$. With the intention of further optimizing the detection conditions, the current responses of FeS-based biosensor generated in varying concentrations of the enzyme stimulants were studied between the ranges from 0 to $0.3 \mathrm{M}$ for $\left(\mathrm{NH}_{4}\right)_{2} \mathrm{SO}_{4}$ and 0 to $0.001 \mathrm{M}$ for $\mathrm{MnCl}_{2} \cdot 4 \mathrm{H}_{2} \mathrm{O}$ in a $1 \mathrm{M}$ glycerol solution, using cyclic voltammetry and constant potential amperometry. Fig. 4. indicates that the highest current responses were obtained at $0.15 \mathrm{M}\left(\mathrm{NH}_{4}\right)_{2} \mathrm{SO}_{4}$ and $0.001 \mathrm{M} \mathrm{MnCl}_{2} .4 \mathrm{H}_{2} \mathrm{O}$, respectively, in nonbuffered conditions. 

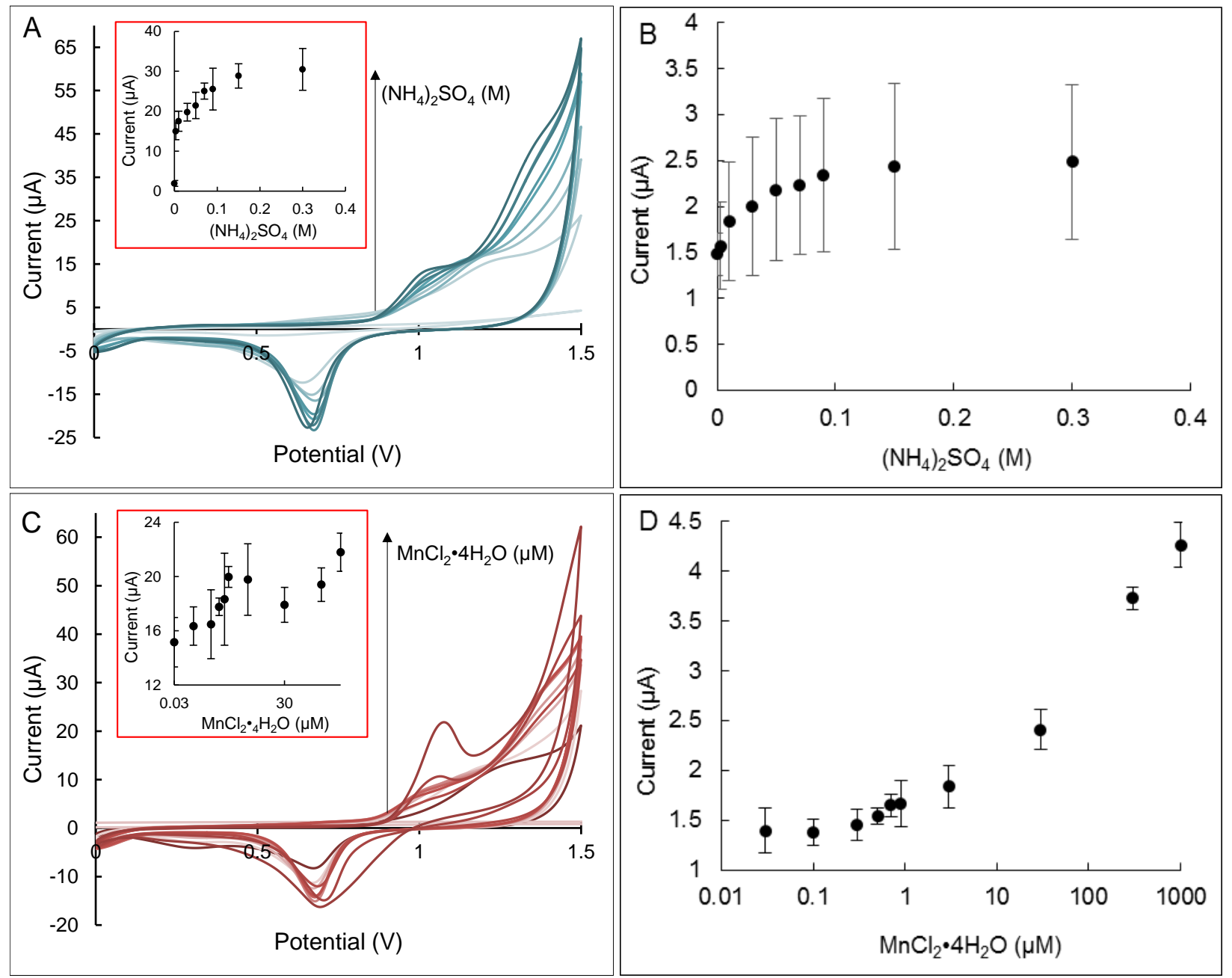

Fig. 4. (A) Cyclic voltammograms of FeS-based biosensor in $(0,0.003,0.01,0.03,0.05,0.07,0.09,0.15$ and 0.3$) \mathrm{M}$ of $\left(\mathrm{NH}_{4}\right)_{2} \mathrm{SO}_{4}$ diluted with water containing $1 \mathrm{M}$ glycerol, scan rate is $50 \mathrm{mV} / \mathrm{s}$. Color intensity of the CV scans increases with increasing concentrations of $\left(\mathrm{NH}_{4}\right)_{2} \mathrm{SO}_{4}$; $(\mathrm{B})$ Equilibrated $(60 \mathrm{~s})$ constant potential amperometric measurements of anodic currents in increasing concentrations of $\left(\mathrm{NH}_{4}\right)_{2} \mathrm{SO}_{4}$ diluted with water containing $1 \mathrm{M}$ glycerol, at $\mathrm{E}=1.3 \mathrm{~V}$; (C) Cyclic voltammograms of FeS-based biosensor in (0, 0.03, 0.1, 0.3, 0.5, 0.7, 0.9, 3, 30, 300 and 1000$) \mu \mathrm{M}$ of $\mathrm{MnCl}_{2} .4 \mathrm{H}_{2} \mathrm{O}$ diluted with water containing $1 \mathrm{M}$ glycerol, scan rate is $50 \mathrm{mV} / \mathrm{s}$. Color intensity of the CV scans increases with increasing concentrations of $\mathrm{MnCl}_{2} \cdot 4 \mathrm{H}_{2} \mathrm{O}$; (D) Equilibrated (60 s) constant potential amperometric measurements of anodic currents in increasing concentrations of $\mathrm{MnCl}_{2} \cdot 4 \mathrm{H}_{2} \mathrm{O}$ diluted with water containing $1 \mathrm{M}$ glycerol, at $\mathrm{E}=1.3 \mathrm{~V}$.

\subsection{The effects of buffers and the $\mathrm{pH}$}

$\mathrm{NAD}^{+}$dependent glycerol dehydrogenase is stable over the $\mathrm{pH}$ range of 7.5-10.5, exhibiting optimum activity at pH 10-10.5 (http://www.sigmaaldrich.com/catalog/product/sigma/g3512?lang=en\&region=US; accessed May 23, 2016). However, the optimum activity of immobilized $\mathrm{NAD}^{+}$-dependent glycerol dehydrogenase wired to the support electrode using $\mathrm{FeS}$ and in the presence of enzyme stimulants is not known. Therefore, the effects of buffers and pH on the current response of the FeS-based glycerol biosensor were studied. Current responses of the biosensor were obtained in potassium phosphate buffer $(\mathrm{pH} 6-8)$ and Tris buffer ( $\mathrm{pH} 8-10)$, using cyclic voltammetry and constant potential amperometry. Benchmark concentrations of the enzyme stimulants and $5 \mathrm{mM}$ glycerol were kept constant during this study. Fig. 5 (and Fig S1 under Supplementary Material) shows current responses of the FeS-based glycerol biosensor to glycerol solution made in different buffers, using cyclic voltammetry. Clearly, the current response in the Tris buffer/pH 8-10 solutions was higher than that in the potassium phosphate buffer/pH 6-8. The striking difference is possibly due to the destructive effect of phosphate buffers on 
$\mathrm{NADH}$, which results in a disruption of the electron transfer by causing irreversibility in the NAD ${ }^{+} / \mathrm{NADH}$ redox cycle (Alivisatos et al. 1965; Passonneau and Lowry 1993). Also, as a result of the Tris buffer/pH 10 generating the maximum current and the optimum $\mathrm{pH}$ for glycerol dehydrogenase being between 1010.5, Tris buffer/pH 10 was chosen as the optimum.
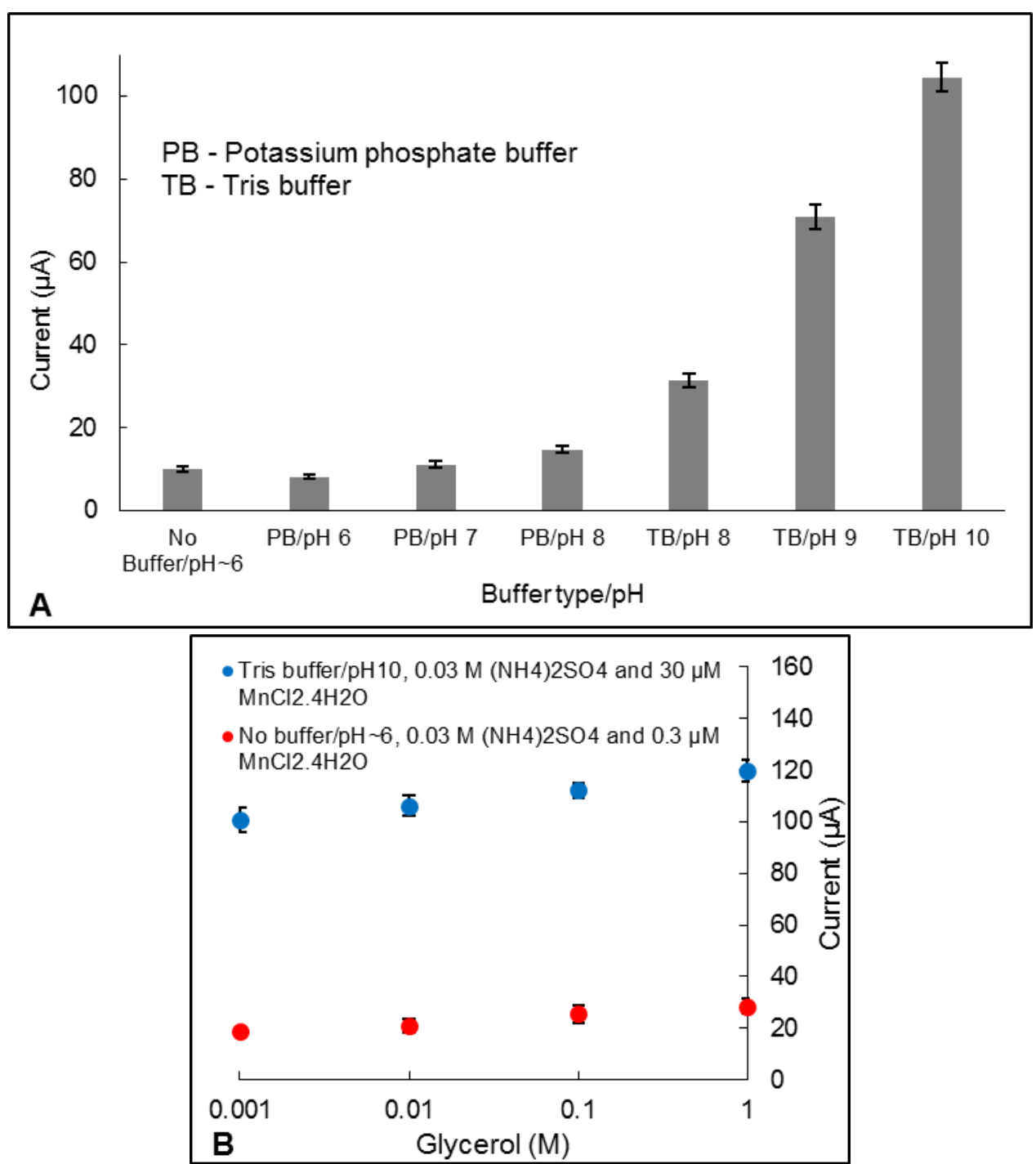

Fig. 5. (A) Effect of $\mathrm{pH} /$ buffers on anodic currents at $\mathrm{E}=1.3 \mathrm{~V}$, generated by FeS-based biosensor in $5 \mathrm{mM}$ glycerol solution containing benchmark concentrations of enzyme stimulants; (B) Peak currents at $1.3 \mathrm{~V}$ vs. glycerol concentrations measured by FeS-based biosensor derived from CV scans between 0 and $1.5 \mathrm{~V}$, scan rate $50 \mathrm{mV} / \mathrm{s}$. A fitting equation for FeS-based biosensor @ $1.3 \mathrm{~V}$ under buffered conditions (Tris buffer/pH10, $0.03 \mathrm{M}\left(\mathrm{NH}_{4}\right)_{2} \mathrm{SO}_{4}$ and $\left.30 \mu \mathrm{M} \mathrm{MnCl}_{2} .4 \mathrm{H}_{2} \mathrm{O}\right)$ is $\mathrm{y}=2.7 \mathrm{ln}(\mathrm{x})+119.2, \mathrm{R}^{2}=0.99$, and non-buffered conditions $\left(\mathrm{pH} 6,0.03 \mathrm{M}\left(\mathrm{NH}_{4}\right)_{2} \mathrm{SO}_{4}\right.$ and $\left.0.3 \mu \mathrm{M} \mathrm{MnCl} 2.4 \mathrm{H}_{2} \mathrm{O}\right)$ is $\mathrm{y}=1.5 \ln (\mathrm{x})+28.6, \mathrm{R}^{2}=0.99$. Error bars depict \pm 1 standard deviation.

When the optimized enzyme stimulant concentrations $\left(0.15 \mathrm{M}\left(\mathrm{NH}_{4}\right)_{2} \mathrm{SO}_{4}\right.$ and $\left.0.001 \mathrm{M} \mathrm{MnCl}_{2} .4 \mathrm{H}_{2} \mathrm{O}\right)$ were combined with the optimal Tris buffer/pH 10, a dark brown precipitate $\left(\mathrm{MnO}_{2}\right)$ was formed in the absence and in the presence of glycerol. We attempted to evaluate the sensing performance of the FeS-based

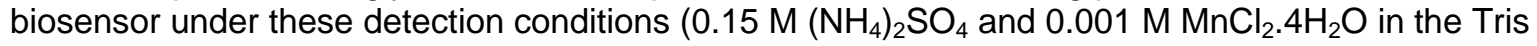
buffer/pH10). However, the biosensor was not able to detect the glycerol satisfactorily. After screening different combinations of enzyme stimulant concentrations in the Tris buffer/pH10, we found that in 0.03 $\mathrm{M}\left(\mathrm{NH}_{4}\right)_{2} \mathrm{SO}_{4}$ and $30 \mu \mathrm{M} \mathrm{MnCl} 2.4 \mathrm{H}_{2} \mathrm{O}$ in the Tris buffer/pH10, the FeS-based glycerol biosensor 
generated a $422 \%$ higher current than the current generated in the non-buffered/benchmark enzyme stimulant concentration conditions (see Fig. 5B) when tested using cyclic voltammetry (non-stirring). Conversely, when tested for sensing performance using constant potential amperometry with stirring, the FeS-based enzyme electrode showed a decreasing current trend with each glycerol injection. The decreasing current trend possibly occurred due to a buffering effect during the glycerol injections.

Hence, we can infer that the optimum performance conditions under stirring remain $0.03 \mathrm{M}\left(\mathrm{NH}_{4}\right)_{2} \mathrm{SO}_{4}$ and $0.3 \mu \mathrm{M} \mathrm{MnCl}_{2} .4 \mathrm{H}_{2} \mathrm{O}$ in non-buffered aqueous electrolyte; whereas, under non-stirring conditions, the

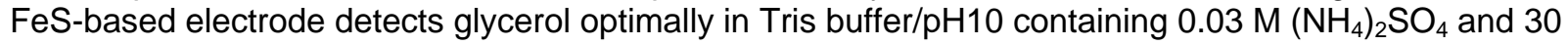
$\mu \mathrm{M} \mathrm{MnCl}_{2} \cdot 4 \mathrm{H}_{2} \mathrm{O}$. Observations made from the cyclic voltammograms (non-stirring) of this study also showed that, at buffered conditions, the applied potential for glycerol detection was lowered from $1.3 \mathrm{~V}$ (non-buffered conditions) to $0.6 \mathrm{~V}$, which is favorable considering that the oxidation of several interferents at $1.3 \mathrm{~V}$ can now be prevented.

\subsection{Interference study}

The effects of commonly considered interferents, typically present in fruit beverages and wine, on glycerol detection by the FeS-based glycerol biosensor was investigated. Considered compounds and their concentrations were $18 \mathrm{~g} / \mathrm{L}$ glucose, $18 \mathrm{~g} / \mathrm{L}$ fructose, $10 \%(\mathrm{v} / \mathrm{v})$ ethanol, and $4 \mathrm{~g} / \mathrm{L}$ acetic acid with $4 \mathrm{~g} / \mathrm{L}$ glycerol, based on the normal concentration ranges of these components in wines and other fruit beverages. The peak currents at $1.3 \mathrm{~V}$ (non-buffered) and $0.6 \mathrm{~V}$ (buffered) as derived from cyclic voltammetry are illustrated in Fig. 6.

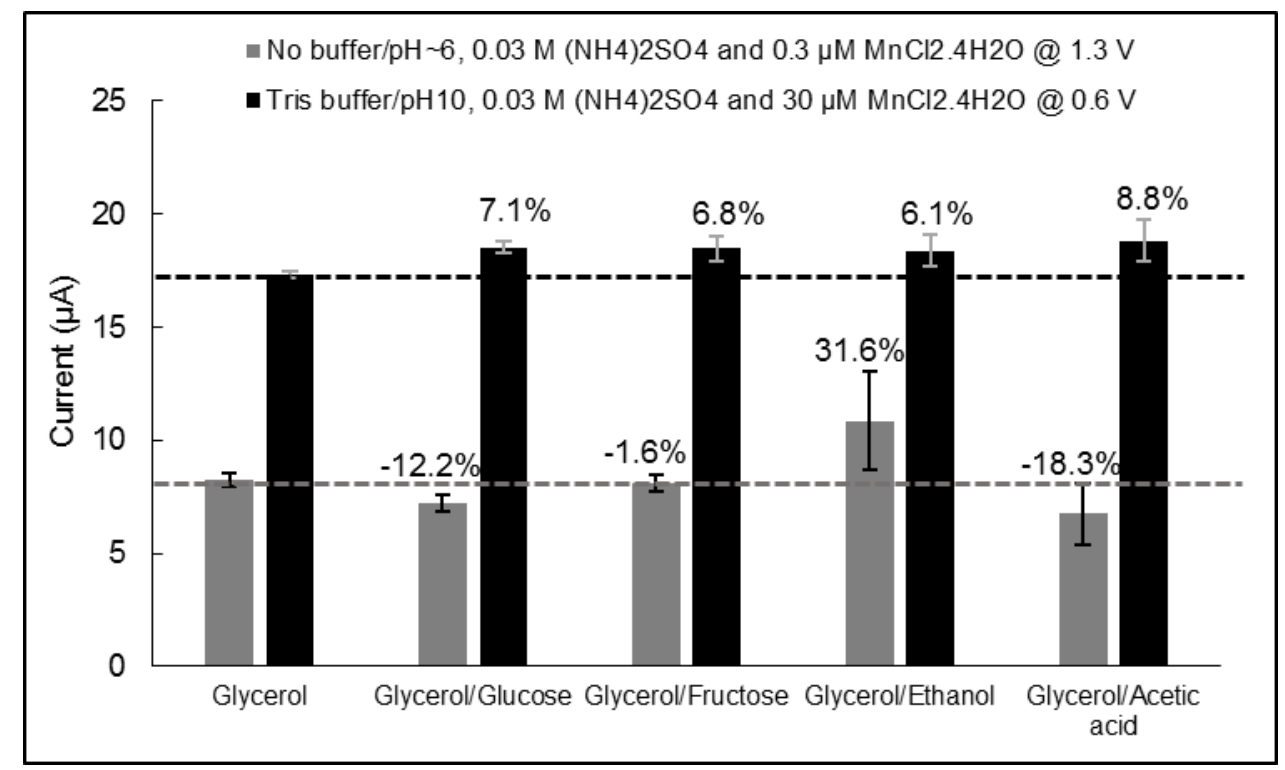

Fig. 6. Effect of the interferents on the current responses generated by the FeS-based biosensor. Current responses were derived from cyclic voltammograms performed from 0 to $1.5 \mathrm{~V}$. Grey color bars depict peak current derived at $1.3 \mathrm{~V}$ under No buffer/pH 6, $0.03 \mathrm{M}\left(\mathrm{NH}_{4}\right)_{2} \mathrm{SO}_{4}$ and $0.3 \mu \mathrm{M} \mathrm{MnCl}_{2} .4 \mathrm{H}_{2} \mathrm{O}$ conditions. Black color bars depict the peak current derived at $0.6 \mathrm{~V}$ under the Tris buffer/pH10, $0.03 \mathrm{M}\left(\mathrm{NH}_{4}\right)_{2} \mathrm{SO}_{4}$ and $30 \mu \mathrm{M} \mathrm{MnCl} 2.4 \mathrm{H}_{2} \mathrm{O}$ conditions.

It can be seen, therefore, that under the Tris buffer/pH10 with $0.03 \mathrm{M}\left(\mathrm{NH}_{4}\right)_{2} \mathrm{SO}_{4}$ and $30 \mu \mathrm{M} \mathrm{MnCl} \mathrm{M}_{2} .4 \mathrm{H}_{2} \mathrm{O}$, the presence of glucose, fructose, ethanol, or acetic acid was over-expressing currents, whereas under no buffer/pH 6, $0.03 \mathrm{M}\left(\mathrm{NH}_{4}\right)_{2} \mathrm{SO}_{4}$ and $0.3 \mu \mathrm{M} \mathrm{MnCl}_{2} .4 \mathrm{H}_{2} \mathrm{O}$ conditions, ethanol was over-expressing, and glucose, fructose and acetic acid were underexpressing the currents. These results indicate that based on the presence/absence of such interferents, reading corrections still have to be made. 


\section{$\underline{4.0 \text { Conclusions }}$}

A glycerol-oxidizing biosensor was fabricated by direct attachment of $\mathrm{NAD}^{+}$-glycerol dehydrogenase coenzyme-apoenzyme complex to supporting gold electrodes, using novel inorganic iron (II) sulfide (FeS)-based single molecular wire. The performance factors of the FeS-based biosensor were compared with those of the PQQ-based biosensor for glycerol detection. Both the biosensors responded linearly to glycerol concentrations as low as $0.34 \mathrm{mM}$ and $0.16 \mathrm{mM}$ with experimentally determined sensitivities of $14 \mu \mathrm{A} . \mathrm{M}^{-1}$ for PQQ-based glycerol biosensor and $25 \mu \mathrm{A} . \mathrm{M}^{-1}$ for FeS-based glycerol biosensor. The response time was calculated to be $0.6 \mathrm{~s}$ for a $\mathrm{PQQ}$-based glycerol biosensor and $1.5 \mathrm{~s}$ for a FeS-based glycerol biosensor. A 77\% increase in sensitivity, a 53\% decrease in detection limit, and a 167\% increase in response time were observed for the FeS-based biosensor when compared to the PQQ-based biosensor for glycerol detection. Such a remarkable improvement in the sensitivity and LOD of the novel FeS-based biosensor compared to the conventional PQQ-based counterpart indicates that FeS-based molecular wires have significant promise as tethers in enzymatic electrodes. However, further optimization studies are required to achieve detection limits comparable to the already existing glycerol biosensors. Considering all of these points, it is clear that both conventionally wired PQQ-based bioanode and the uniquely wired FeS-based bioanode can be successfully used as biosensors for glycerol detection. Excitingly, the performance of the FeS-based glycerol biosensor was found to be far more superior when compared to the conventional PQQ-based one. For further optimization, the electrochemical performance of the FeS-based glycerol biosensor was studied under different concentrations of glycerol, along with the effects of applied potential and scan rate on the current response. Linearly increasing anodic and cathodic peak currents with increasing scan rates indicated that the electrode kinetics are controlled by diffusion. The optimum performance conditions were $0.03 \mathrm{M}$ $\left(\mathrm{NH}_{4}\right)_{2} \mathrm{SO}_{4}$ and $0.3 \mu \mathrm{M} \mathrm{MnCl}_{2} .4 \mathrm{H}_{2} \mathrm{O}$ in non-buffered aqueous electrolyte under stirring, whereas under non-stirring, the optimal conditions were in Tris buffer at $\mathrm{pH} 10$ with $0.03 \mathrm{M}\left(\mathrm{NH}_{4}\right)_{2} \mathrm{SO}_{4}$ and $30 \mu \mathrm{M}$ $\mathrm{MnCl}_{2} \cdot 4 \mathrm{H}_{2} \mathrm{O}$. Further analysis indicated that the FeS-based wiring system in unstirred conditions was staying intact and performing the electron transport unfettered even under relatively extreme $\mathrm{pH}$ conditions, i.e., 10, at which point the GIDH enzyme performance becomes optimal. An interference study showed acceptable interference from glucose, fructose, ethanol, and acetic acid under buffered conditions and relatively higher interference from glucose, ethanol, and acetic acid under non-buffered conditions. Additional studies are needed to elucidate the reason(s) for the increased response time with the FeS-based electrode and also to limit interferences of commonly found analytes before these electrodes can be utilized for real world biosensing applications.

\section{Acknowledgments}

This article and its research are based on work supported by the National Science Foundation under Grant CBET-1511303.

\section{References}

Alivisatos, S.G., Ungar, F., Abraham, G.J., 1965. Spontaneous Reactions of 1, 3-Substituted 1, 4Dihydropyridines with Acids in Water at Neutrality. I. Kinetic Analysis and Mechanism of the Reactions of Dihydronicotinamide-Adenine Dinucleotide with Orthophosphates*. Biochemistry 4(12), 2616-2630. Álvarez-González, M.I., Saidman, S.B., Lobo-Castañón, M.J., Miranda-Ordieres, A.J., Tuñón-Blanco, P., 2000. Electrocatalytic detection of NADH and glycerol by NAD+-modified carbon electrodes. Analytical chemistry 72(3), 520-527.

Atkins, P., 1998. Physical Chemistry. 6th. Oxford University Press.

Bardeletti, G., Séchaud, F., Coulet, P.R., 1991. Amperometric enzyme electrodes for substrate and enzyme activity determinations. Biosensor principles and applications, 7-45.

Cline, J.F., Hoffman, B.M., Mims, W.B., LaHaie, E., Ballou, D.P., Fee, J.A., 1985. Evidence for N coordination to $\mathrm{Fe}$ in the [2Fe-2S] clusters of Thermus Rieske protein and phthalate dioxygenase from Pseudomonas. Journal of Biological Chemistry 260(6), 3251-3254. 
Eftekhari, A., 2001. Glycerol biosensor based on glycerol dehydrogenase incorporated into polyaniline modified aluminum electrode using hexacyanoferrate as mediator. Sensors and Actuators B: Chemical 80(3), 283-289.

Graham, D., Dingman, S., 2006. Material Matters. Sigma Aldrich.

Johnston, D.E., Strachan, D.R., Johnson, A.T.C., 2007. Parallel fabrication of nanogap electrodes. Nano letters 7, 2474-2477.

Katrlík, J., Mastihuba, V., Voštiar, I., Šefčovičová, J., Štefuca, V., Gemeiner, P., 2006. Amperometric biosensors based on two different enzyme systems and their use for glycerol determination in samples from biotechnological fermentation process. Analytica Chimica Acta 566(1), 11-18.

Lavrenova, L.G., Ikorskii, V.N., Varnek, V.A., Oglezneva, I.M., Larionov, S.V., 1986. High-temperature spin transition in coordination compounds of iron(II) with triazoles. Journal Name: Sov. J. Coordinat. Chem.; (United States); Journal Volume: 12:2; Other Information: Translated from Koordinatsionnaya Khimiya, 12: No. 2, 207-215(Feb 1986), Medium: X; Size: Pages: 119-127.

Love, J.C., Estroff, L.A., Kriebel, J.K., Nuzzo, R.G., Whitesides, G.M., 2005. Self-Assembled Monolayers of Thiolates on Metals as a Form of Nanotechnology. Chemical Reviews 105(4), 1103-1170.

Mahadevan, A., Fernando, T., Fernando, S., 2016. Iron-sulfur-based single molecular wires for enhancing charge transport in enzyme-based bioelectronic systems. Biosensors and Bioelectronics 78, 477-482.

Mahadevan, A., Gunawardena, D.A., Karthikeyan, R., Fernando, S., 2015. Potentiometric vs amperometric sensing of glycerol using glycerol dehydrogenase immobilized via layer-by-layer selfassembly. Microchimica Acta 182(3-4), 831-839.

Marcus, R.A., Sutin, N., 1985. Electron transfers in chemistry and biology. Biochimica et Biophysica Acta (BBA)-Reviews on Bioenergetics 811(3), 265-322.

Marlin, D.S., Olmstead, M.M., Mascharak, P.K., 1999. Carboxamido Nitrogens Are Good Donors for Fe(III): Syntheses, Structures, and Properties of Two Low-Spin Nonmacrocyclic Iron(III) Complexes with Tetracarboxamido-N Coordination. Inorganic chemistry 38(13), 3258-3260.

Meyer, J., 2008. Iron-sulfur protein folds, iron-sulfur chemistry, and evolution. J Biol Inorg Chem 13(2), 157-170.

Minteer, S.D., Liaw, B.Y., Cooney, M.J., 2007. Enzyme-based biofuel cells. Current Opinion in Biotechnology 18(3), 228-234

Mrksich, M., Chen, C.S., Xia, Y., Dike, L.E., Ingber, D.E., Whitesides, G.M., 1996. Controlling cell attachment on contoured surfaces with self-assembled monolayers of alkanethiolates on gold.

Proceedings of the National Academy of Sciences 93(20), 10775-10778.

Niculescu, M., Sigina, S., Csöregi, E., 2003. Glycerol dehydrogenase based amperometric biosensor for monitoring of glycerol in alcoholic beverages. Analytical letters 36(9), 1721-1737.

Park, H., Lim, A.K.L., Alivisatos, A.P., Park, J., McEuen, P.L., 1999. Fabrication of metallic electrodes with nanometer separation by electromigration. Appl. Phys. Lett. 75, 303-304.

Passonneau, J.V., Lowry, O.H., 1993. Enzymatic analysis: a practical guide. Springer Science \& Business Media.

Prodromidis, M., Stalikas, C., Tzouwara-Karayanni, S., Karayannis, M., 1996. Determination of glycerol in alcoholic beverages using packed bed reactors with immobilized glycerol dehydrogenase and an amperometric FIA system. Talanta 43(1), 27-33.

Radoi, A., Compagnone, D., Devic, E., Palleschi, G., 2007. Low potential detection of NADH with Prussian Blue bulk modified screen-printed electrodes and recombinant NADH oxidase from Thermus thermophilus. Sensors and Actuators B: Chemical 121(2), 501-506.

Reed, M.A., Zhou, C., Muller, C.J., Burgin, T.P., Tour, J.M., 1997. Conductance of a molecular junction. Science 278, 252-254.

Riklin, A., Katz, E., Willner, I., Stocker, A., Buckmann, A.F., 1995. Improving enzyme-electrode contact redox modifications cofactors. Nature ( 376, ), 672-675.

Ronkainen, N.J., Halsall, H.B., Heineman, W.R., 2010. Electrochemical biosensors. Chemical Society Reviews 39(5), 1747-1763.

Tour, J.M., Jones, L., Pearson, D.L., Lamba, J.J.S., Burgin, T.P., Whitesides, G.M., Allara, D.L., Parikh, A.N., Atre, S., 1995. Self-Assembled Monolayers and Multilayers of Conjugated Thiols, .alpha.,.omega.Dithiols, and Thioacetyl-Containing Adsorbates. Understanding Attachments between Potential Molecular Wires and Gold Surfaces. Journal of the American Chemical Society 117(37), 9529-9534. 
Vanegas, D.C., Taguchi, M., Chaturvedi, P., Burrs, S., Tan, M., Yamaguchi, H., McLamore, E.S., 2014. A comparative study of carbon-platinum hybrid nanostructure architecture for amperometric biosensing. Analyst 139(3), 660-667.

Zhong, C.-J., Porter, M.D., 1994. Evidence for Carbon-Sulfur Bond Cleavage in Spontaneously Adsorbed Organosulfide-Based Monolayers at Gold. Journal of the American Chemical Society 116(25), 1161611617.

\section{Web reference(s)}

http://www.sigmaaldrich.com/catalog/product/sigma/g3512?lang=en\&region=US; accessed May 23, 2016

\section{Appendices}

\section{Figures}

Fig. 1: (A) A schematic of wiring systems. (a) Complex conventional wiring of the coenzyme $\mathrm{NAD}^{+}$to a gold electrode using a series of molecules, including a cystamine linker, a PQQ mediator, and a phenyl boronic acid linker; (b) Simplified wiring of a $\mathrm{NAD}^{+}$coenzyme directly onto the gold electrode by a multifunctional mediator, FeS. Reprinted with permission from ref (Mahadevan et al. 2016). Copyright 2015 Elsevier B.V; Surface morphology of (B) bare Au surface and (C) an enzyme immobilized Au surface examined via FE-SEM.

Fig. 2: (A) Amperometric responses to increments of $0.001 \mathrm{M}$ glycerol at $\mathrm{E}=1.3 \mathrm{~V}$; (B) Calibration plots for current responses generated by the FeS-based biosensor and PQQ-based biosensor as a function of glycerol concentration; (C) Summary of the biosensor performance obtained from a dynamic CPA test.

Fig. 3. (A) Cyclic voltammograms for FeS-based biosensor in increasing concentrations of glycerol $(a-0$ $\mathrm{M}, \mathrm{b}-0.001 \mathrm{M}, \mathrm{c}-0.01 \mathrm{M}, \mathrm{d}-0.1 \mathrm{M}$ and $\mathrm{e}-1 \mathrm{M}$ ) diluted with water containing enzyme stimulants at benchmark concentrations. Scan rate is $50 \mathrm{mV} / \mathrm{s}$. (B) Effect of applied potential, ranging from 0 to $1.5 \mathrm{~V}$ on the current response of the FeS-based biosensor in the presence of $1 \mathrm{M}$ glycerol. (C) Effect of scan rates $\left(10,30,50,70,90,110,130\right.$, and 150) $\mathrm{mVs}^{-1}$ on the current response of the FeS-based biosensor in the presence of $1 \mathrm{M}$ glycerol where the color intensity of the CV scan increases with an increasing scan rate in the figure. (D) Anodic and cathodic peak currents plotted with respect to the square root of the scan rate $\left(v^{1 / 2}\right)$.

Fig. 4. (A) Cyclic voltammograms of FeS-based biosensor in $(0,0.003,0.01,0.03,0.05,0.07,0.09,0.15$ and 0.3$) \mathrm{M}$ of $\left(\mathrm{NH}_{4}\right)_{2} \mathrm{SO}_{4}$ diluted with water containing $1 \mathrm{M}$ glycerol, scan rate is $50 \mathrm{mV} / \mathrm{s}$. Color intensity of the CV scans increases with increasing concentrations of $\left(\mathrm{NH}_{4}\right)_{2} \mathrm{SO}_{4}$. (B) Equilibrated $(60 \mathrm{~s})$ constant potential amperometric measurements of anodic currents in increasing concentrations of $\left(\mathrm{NH}_{4}\right)_{2} \mathrm{SO}_{4}$ diluted with water containing $1 \mathrm{M}$ glycerol, at $\mathrm{E}=1.3 \mathrm{~V}$. (C) Cyclic voltammograms of FeS-based biosensor in $\left(0,0.03,0.1,0.3,0.5,0.7,0.9,3,30,300\right.$ and 1000) $\mu \mathrm{M}$ of $\mathrm{MnCl}_{2} .4 \mathrm{H}_{2} \mathrm{O}$ diluted with water containing $1 \mathrm{M}$ glycerol, scan rate is $50 \mathrm{mV} / \mathrm{s}$. Color intensity of the CV scans increases with increasing concentrations of $\mathrm{MnCl}_{2} \cdot 4 \mathrm{H}_{2} \mathrm{O}$. (D) Equilibrated (60 s) constant potential amperometric measurements of anodic currents in increasing concentrations of $\mathrm{MnCl}_{2} \cdot 4 \mathrm{H}_{2} \mathrm{O}$ diluted with water containing $1 \mathrm{M}$ glycerol, at $\mathrm{E}=1.3 \mathrm{~V}$.

Fig. 5. (A) Effect of $\mathrm{pH} /$ buffers on anodic currents at $\mathrm{E}=1.3 \mathrm{~V}$, generated by FeS-based biosensor in $5 \mathrm{mM}$ glycerol solution containing benchmark concentrations of enzyme stimulants; (B) Peak currents at $1.3 \mathrm{~V}$ vs. glycerol concentrations measured by FeS-based biosensor derived from CV scans between 0 and 1.5 $\mathrm{V}$, scan rate $50 \mathrm{mV} / \mathrm{s}$. A fitting equation for FeS-based biosensor @ $1.3 \mathrm{~V}$ under buffered conditions (Tris buffer/pH10, $0.03 \mathrm{M}\left(\mathrm{NH}_{4}\right)_{2} \mathrm{SO}_{4}$ and $\left.30 \mu \mathrm{M} \mathrm{MnCl}_{2} \cdot 4 \mathrm{H}_{2} \mathrm{O}\right)$ is $\mathrm{y}=2.7 \ln (\mathrm{x})+119.2, \mathrm{R}^{2}=0.99$, and nonbuffered conditions $\left(\mathrm{pH} 6,0.03 \mathrm{M}\left(\mathrm{NH}_{4}\right)_{2} \mathrm{SO}_{4}\right.$ and $\left.0.3 \mu \mathrm{M} \mathrm{MnCl} 2.4 \mathrm{H}_{2} \mathrm{O}\right)$ is $\mathrm{y}=1.5 \ln (\mathrm{x})+28.6, \mathrm{R}^{2}=0.99$. Error bars depict \pm 1 standard deviation. 
Fig. 6. Effect of interferents on the current responses generated by FeS-based biosensor. Current responses were derived from cyclic voltammograms performed from 0 to $1.5 \mathrm{~V}$ and peak current chosen according to the electrolyte conditions. Grey color bars depict current derived at $1.3 \mathrm{~V}$ under No buffer/pH 6, $0.03 \mathrm{M}\left(\mathrm{NH}_{4}\right)_{2} \mathrm{SO}_{4}$ and $0.3 \mu \mathrm{M} \mathrm{MnCl}_{2} .4 \mathrm{H}_{2} \mathrm{O}$ conditions. Black color bars depict the current derived at $0.6 \mathrm{~V}$ under Tris buffer/pH10, $0.03 \mathrm{M}\left(\mathrm{NH}_{4}\right)_{2} \mathrm{SO}_{4}$ and $30 \mu \mathrm{M} \mathrm{MnCl}_{2} .4 \mathrm{H}_{2} \mathrm{O}$ conditions. 